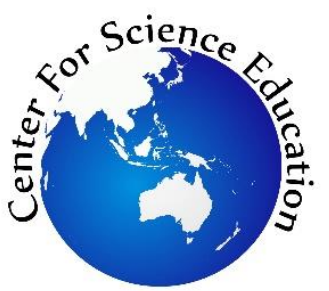

Tersedia online di EDUSAINS

Website: http://journal.uinjkt.ac.id/index.php/edusains

EDUSAINS,12(1), 2020, 54-63

Research Artikel

EDUS:

\title{
PENGEMBANGAN LITERASI SAINS DAN IDENTITAS BUDAYA SISWA MELALUI PENDEKATAN ETNO-PEDAGOGI DALAM PEMBELAJARAN SAINS
}

\section{SCIENCE LITERACY AND STUDENT CULTURAL IDENTITY DEVELOPMENT THROUGH ETHNO-PEDAGOGY APPROACH IN SCIENCE LEARNING}

\author{
Yuli Rahmawati $^{1 *}$, Achmad Ridwan ${ }^{1}$, Sylvia Faustine ${ }^{1}$, Sitti Syarah $^{2}$, Ibrahim $^{2}$, Pramita \\ Cucu Mawarni ${ }^{3}$ \\ ${ }^{1}$ Universitas Negeri Jakarta, Jakarta, Indonesia \\ ${ }^{2}$ SMPN 4 Bolo, , Nusa Tenggara Barat, Indonesia \\ ${ }^{3}$ SMA Bakti Mulya 400, Jakarta, Indonesia \\ *yrahmawati@unj.ac.id
}

\begin{abstract}
This study aims to develop and apply ethno-pedagogy learning models in science learning to develop scientific literacy and students' cultural identity in the solar system topic. The study was conducted at SMPN 4 Bolo in the even semester of the 2018/2019 school year with 26 research subjects consisting of grade seven students. The study was conducted using qualitative analysis methods by collecting data through observation, reflective journals, student interviews, and scientific literacy tests. The ethnopedagogy model is carried out through five stages of learning: self-identification, Content Integration, Collaboration, Dialogue, and Reflection. The results showed that the Etnopedagogy learning model impacted the development of students' scientific literacy and student's cultural identity. Based on the students' scientific literacy test as a whole showed that as many as $6.25 \%$ of students reached excellent levels and $31.25 \%$ of students reached good levels, $50 \%$ of students reached sufficient levels, $12.50 \%$ of students reached unfavorable levels, and there were none of the students who are at a not very good level. Science learning with the Ethno Pedagogy model provides opportunities for students to develop scientific literacy and learn to understand their cultural identity, foster a sense of love and pride for Indonesia, and responsibility to preserve its culture.
\end{abstract}

Keywords: ethno-pedagogy; science learning; science literacy; culture; cultural identity.

\begin{abstract}
Abstrak
Penelitian ini bertujuan untuk mengembangkan dan menerapkan model pembelajaran etnopedagogi dalam pembelajaran IPA untuk mengembangkan literasi sains dan identitas budaya siswa pada materi sistem tata surya. Penelitian dilaksanakan di SMPN 4 Bolo pada semester genap tahun ajaran 2018/2019 dengan subyek penelitian terdiri dari 26 orang siswa kelas VII. Penelitian dilakukan dengan menggunakan metode analisis kualitatif dengan mengumpulkan data melalui observasi, reflektif jurnal, wawancara siswa, dan tes literasi sains. Model etnopedagogi dilakukan melalui lima tahapan pembelajaran, yaitu selfidentification, Content Integration, Collaboration, Dialogue, dan Reflection. Hasil penelitian menunjukkan bahwa model pembelajaran Etnopedagogi memiliki dampak dalam pengembangan literasi sains siswa dan identitas budaya siswa. Berdasarkan tes literasi sains siswa secara keseluruhan menunjukkan sebanyak dapat diketahui bahwa sebanyak 6,25\% siswa mencapai level baik sekali dan $31,25 \%$ siswa mencapai level baik, 50\% siswa mencapai level cukup, 12,50\% siswa mencapai level kurang baik, dan tidak ada lagi siswa yang berada pada level kurang baik sekali. Pembelajaran sains dengan model Etnopdagogi memberikan kesempatan kepada siswa untuk mengembangkan literasi sains dan belajar untuk memahami identitas budayanya, menumbuhkan rasa cinta tanah air, bangga dan tanggung jawab untuk melestarikan budayanya.
\end{abstract}

Kata Kunci: etnopedagogi; pembelajaran IPA; literasi sains; budaya; identitas budaya

Permalink/DOI: http://doi.org/10.15408/es.v12i1.12428 


\section{PENDAHULUAN}

Pendidikan sains memiliki peran penting dalam pengembangan potensi siswa untuk lebih siap memasuki dunia kehidupannya. Hal tersebut juga berkontribusi untuk mengembangkan kemampuan memahami dan menggunakan sains dalam kehidupan sehari-hari dan memiliki tanggung jawab sosial. Pengajaran sains berfokus pada kemampuan siswa untuk menggunakan kemampuan saintifik dalam kehidupan nyata. Hal ini berkaitan dengan literasi sains yang merepresentasikan kemampuan menggunakan fakta dan data untuk mengevaluasi kualitas informasi yang diterima. Kemampuan individu untuk memahami hukum sains, teori dan fenomena juga dideskripsikan melalui kemampuan literasi sains. Pendidik sains mempunyai peranan yang penting dalam mendidik siswa untuk mengembangkan kemampuan literasi sains (Martinez-Hernandez et $a l, 2015)$.

Literasi sains yang berkaitan dengan budaya merupakan salah satu klasifikasi dari empat kategori literasi sains (Dragoş \& Mih, 2015; Shen, 1975; Trefil, 2008). Pendidikan multikultural melalui literasi sains yang berkaitan dengan budaya telah dikembangkan untuk membantu sekolah mengembangkan jenis budaya inklusif dan berpikiran terbuka yang, jika menyebar, dapat berkontribusi untuk mencipakan situasi yang lebih damai, kohesif, dan demokratis (Elmi, 2010). Pendidikan multikultural merupakan masalah penting karena Indonesia memiliki keragaman dan keunikan budaya.

Etnopedagogi dapat menjadi alat yang efektif untuk menghubungkan sains dan budaya. Berdasarkan pada Klara et.al (2015), etnopedagogi terhubung dengan latar belakang kelompok etnis tertentu. Menurut Akhmetova (2014), etnopedagogi dapat mengembangkan sikap yang benar terhadap nilai-nilai budaya nasional. Siswa ditantang untuk memikirkan kembali pentingnya nilai-nilai tradisional pada budaya mereka yang dihubungkan dalam kehidupan mereka sendiri dalam penelitian ini (Toleubekova \& Zhumataeva, 2018).

Etnopedagogi sendiri meneliti ilmu tentang pengalaman hidup orang-orang, pendidikan, standar etika dan lingkungan serta aturan perilaku generasi muda di lingkungan alam dan sosial. Berdasarkan Burger (1971), tujuan etnopedagogi adalah pencapaian sinkretisme atau rekonsiliasi dua atau lebih elemen budaya atau sistem dengan modifikasi keduanya. Etnopedagogi dapat mempelajari proses interaksi dalam lingkungan pendidikan poli etnik dan kekhasan nasional pendidikan yang telah berkembang (Valeeva, 2015).

Penelitian ini menggunakan etnopedagogi diintegrasikan ke dalam model pembelajaran berbasis proyek dalam kelompok yang melibatkan kebudayaan dalam pembelajaran IPA pada materi tata surya yang jarang dikaitkan dengan budaya Indonesia berdasarkan observasi yang telah dilakukan di SMPN 4 Bolo, NTB. Menurut (Yuli Rahmawati et al, 2015), dialog yang terjadi antar siswa dalam kelompok diperlukan untuk meningkatkan keterlibatan siswa dalam pembelajaran IPA. Penelitian ini mengintegrasikan apa yang dilakukan masyarakat dan tradisi di beberapa daerah seperti Yogyakarta, Bima, Solo, Bugis dan Tidore yang berhubungan dengan pelajaran tata surya.

\section{METODE}

Penelitian ini menggunakan metodologi penelitian kualitatif dengan beberapa metode pengumpulan data yang terdiri dari jurnal reflektif, wawancara, dan tes literasi sains. Penelitian dilaksanakan di SMPN 4 Bolo pada semester genap tahun ajaran 2018/2019 dengan subyek penelitian terdiri dari 26 orang siswa kelas VII.. Tahapan pembelajaran etnopedagogi, diintegrasikan ke dalam model pembelajaran berbasis proyek terdiri dari lima langkah pembelajaran seperti yang ditunjukkan pada Gambar 1.

Pada tahap awal, peneliti melakukan wawancara dengan guru sains dan melakukan observasi pada budaya kelas. Selain itu, siswa diberi lembar kerja yang diisi dengan pertanyaan tentang diri mereka seperti karakter, bagaimana belajar di rumah dan sekolah, hubungan mereka dengan teman-teman di kelas, budaya. Pada tahap implementasi, data dari jurnal reflektif dan catatan 
lapangan dikumpulkan melalui proses pembelajaran sains. Siswa dibagi menjadi 5 kelompok untuk membahas tentang artikel yang diberikan tentang fenomena tata surya yang terintegrasi dengan budaya dari Bugis, Tidore, Yogyakarta, Solo, dan Bima.

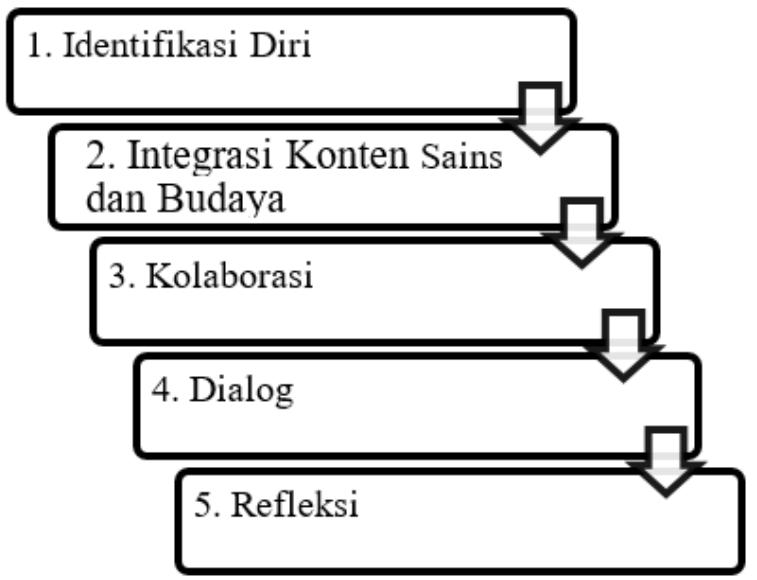

Gambar 1. Tahapan Pembelajaran Etnopedagogi

Tahap berikutnya, siswa melakukan proyek untuk membuat model tata surya dengan memberikan materi seperti tanah liat, gabus, cat air, dll. Selanjutnya, siswa mempresentasikan dan menjelaskan model dan konsep dari proyek mereka di depan kelas. Akhirnya, pada fase setelah kolaborasi dan dialog, data melalui wawancara semi-terstruktur, jurnal reflektif, dan tes literasi sains dikumpulkan. Data tersebut menunjukan hasil dari apa yang mereka lakukan dalam proses pembelajaran dalam aspek kerja tim, pemahaman mereka antara budaya dan konsep sains, dan pengembangan karakter yang mereka bangun setelah proses pembelajaran.

\section{HASIL DAN PEMBAHASAN}

Pada penelitian ini ditekankan pada hasil literasi sains siswa yang muncul dalam setiap pembelajaran dan hasil analisis identitas budaya siswa.

\section{Literasi Sains Siswa}

Tahap analisis dilakukan setelah peneliti memperoleh jawaban atas soal literasi sains yang diberikan kepada siswa. Hasil tes ini digunakan untuk menganalisis tingkat pencapaian literasi sains siswa. Soal yang diberikan adalah 4 soal essay yang dibagi berdasarkan rubrik literasi sains yang dikembangkan oleh Shwartz et .al (2006) yaitu berupa gagasan ilmiah umum, karakteristik sains, konteks sains, kemampuan belajar tingkat tinggi, dan aspek afektif. Tingkat pencapaian literasi sains dibagi ke dalam 5 kategori, yaitu kurang baik sekali, kurang baik, cukup, baik, dan baik sekali.

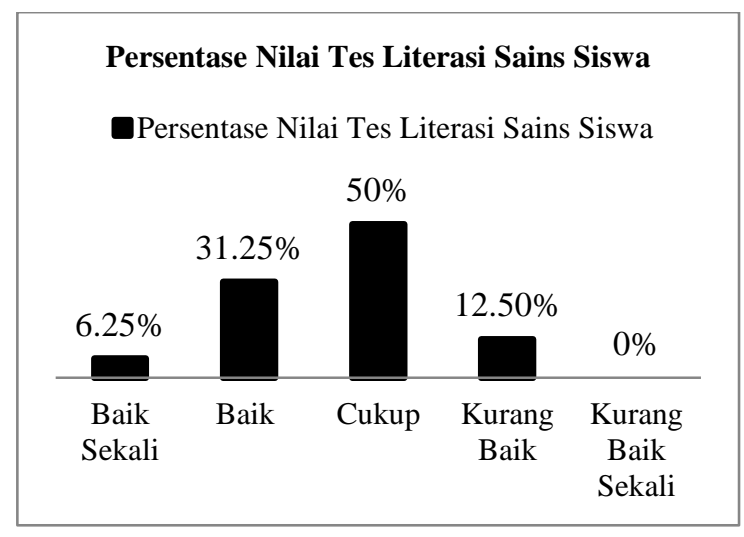

Gambar 2. Histogram Level Pencapaian Literasi Sains Siswa

Berdasarkan Gambar 2 di atas, dapat diketahui bahwa sebanyak $6,25 \%$ siswa dapat dikategorikan sudah mampu mencapai tingkat yang sangat baik dan $31,25 \%$ di tingkat yang baik. Hal ini menunjukkan bahwa siswa sebanyak total $37,50 \%$ sudah mampu untuk melakukan penyelidikan ilmiah, membuat gagasan umum dari hasil temuan, menjelaskan fenomena dalam kehidupan berdasarkan pengetahuan sains, dan mampu menjelaskan dampak serta aplikasi ilmu sains dalam kehidupan sehari-hari.

Berikut merupakan analisis hasil literasi sains siswa dalam pembelajaran IPA dengan menggunakan model etnopedagogi berdasarkan rubrik (Shwartz et al, 2006).

\section{General Scientific Ideas}

Shwartz et.al (2006) menyatakan bahwa dalam aspek ini siswa mampu melakukan penyelidikan ilmiah, membuat generalisasi temuan, mengajukan teori untuk menjelaskan fenomena alam, serta menggunakan pengetahuan sains untuk menjelaskan fenomena lain di beberapa area seperti ilmu bumi dan ilmu mengenai mahluk hidup. Hasil tes literasi sains pada aspek general scientific ideas menunjukkan $12,5 \%$ siswa yang telah mencapai 
tingkatan baik sekali. Hal tersebut juga dibuktikan dengan hasil lembar kerja salah satu siswa dalam menjawab soal literasi sains yang diberikan seperti yang ada di bawah ini.

\section{Kategori Baik Sekali}

"2A. Planet saturnus (D) adalah planet yang memiliki cincin, kala rotasi 10 jam, dan kala revolusi 30 tahun. Planet venus $(C)$ adalah planet yang tidak mempunyai satelit dan dijuluki bintang kejora. Planet merkurius (B) merupakan planet terkecil, tidak memiliki atmosfer dan suhu yang ekstrim. Planet mars (A) adalah planet yang diberi julukan planet merah dan ukurannya hampir sama dengan bumi.

2B. Belum ada mahluk hidup yang bisa tinggal di planet selain di bumi karena semua yang dibutuhkan untuk menunjang kehidupan terdapat di bumi seperti udara, air, dan tumbuhan. Hanya Bumi yang memiliki itu dan planet lain tidak." (Lembar Kerja Siswa 16, 16 April 2019)

Berdasarkan lembar kerja di atas dapat diartikan bahwa siswa sudah memenuhi komponen literasi sains menurut Norris \& Phillips (2003) yaitu, mampu melakukan penyelidikan ilmiah dalam mengidentifikasi ciri-ciri planet dalam sistem tata surya, membuat kesimpulan terkait bumi yang menjadi tempat satu-satunya bagi mahluk hidup, dan mengajukan teori untuk menjelaskan fenomena tersebut. Siswa yang mencapai tingkatan baik yaitu $37,5 \%$ siswa yang dibuktikan oleh hasil tes literasi sains salah satu siswa sebagai berikut.

\section{Kategori Baik}

"2A. Planet saturnus (D), planet merkurius $(B)$, planet mars $(A)$, planet venus $(C)$.

2B. Belum ada mahluk hidup yang bisa tinggal di planet selain di bumi karena bumi sangat kaya akan sumber daya alam yang meluas dan jauh dari matahari."'(Lembar Kerja Siswa 01, 16 April 2019)

Siswa $01 \mathrm{di}$ atas memiliki hasil tes yang tergolong tingkatan baik yang artinya siswa dapat melakukan penyelidikan ilmiah terkait penentuan planet berdasarkan karakteristiknya, membuat kesimpulan dan mencoba untuk menjelaskan fenomena alam semesta dan menggunakan pengetahuan IPA yang siswa pahami untuk berdiskusi fenomena dalam bidang biologi mengenai penjelasan sumber daya alam di bumi. literasi ilmiah sebagai syarat untuk dapat beradaptasi dengan tantangan dunia yang berubah dengan cepat dan literasi ilmiah sejalan dengan pengembangan keterampilan hidup (D S Rychen \& Salganik, 2003). Namun ada siswa sebanyak $18,75 \%$ siswa dalam tingkatan cukup dan kurang baik. Hal ini dibuktikan dengan hasil tes siswa dalam lembar kerja sebagai berikut.

\section{Kategori Cukup}

"2A. Menurut saya yang D merupakan ciriciri planet saturnus karena kala rotasi 10 jam, kala revolusi 30 tahun dan mempunyai cincin yang indah. C merupakan ciri-ciri planet venus karena sudut elongasi terbesar 48 derajat, tidak mempunyai satelit, dan dijuluki bintang pagi dan bintang sore. $B$ merupakan ciri-ciri planet merkurius karena tidak memiliki atmosfer, perbedaan suhu bagian terang dan gelap yang kontras dan planet terkecil dalam tata surya. A merupakan ciri-ciri planet mars karena periode rotasinya hampir sama dengan rotasi bumi, memiliki satelit phobos dan demos, dan diberi julukan planet merah.

2B. Belum ada mahluk hidup yang bisa tinggal di planet selain di bumi karena adanya perbedaan suhu pada setiap planet." (Lembar

\section{Kerja Siswa 06, 16 April 2019)}

\section{Kategori Kurang Baik}

“2A. Planet saturnus $(D)$, planet venus $(C)$, planet merkurius (B), planet mars (A). Saturnus adalah planet yang mempunyai cincin. Venus adalah planet yang diberi julukan bintang pagi dan bintang sore. Merkurius adalah planet terkecil. Mars adalah planet yang dijuluki sebagai planet merah.

2B. Belum ada mahluk hidup yang bisa tinggal di planet selain di bumi karena planet lain banyak debu dan tidak ada satupun mahluk hidup yang menempati planet itu." (Lembar Kerja Siswa 20, 16 April 2019)

Hasil lembar kerja siswa di atas menunjukkan bahwa siswa telah mencoba 
melakukan penyelidikan terhadap informasi karakteristik planet pada soal, namun siswa tidak dapat membuat generalisasi temuannya yaitu tidak dapat menuliskan penjelasan dan teori secara dertail mengenai alasan mengapa bumi merupakan planet yang dapat ditempati oleh mahluk hidup.

\section{Characteristic of Science}

Aspek characteristic of science menjelaskan kemampuan siswa dalam memahami dan menerangkan fenomena sains yang dikaitkan dengan struktur dan proses dalam kehidupan. Kemampuan literasi sains siswa terlihat ketika siswa mampu menggunakan konsep sains dengan nilai budaya untuk membuat keputusan yang bertanggung jawab dalam kehidupan sehari-hari (Holbrook \& Rannikmae, 2009). Hasil analisis Dalam penelitian ini menunjukkan bahwa siswa mampu menjelaskan fenomena benda makroskopis dalam materi tata surya. Hal ini dibuktikan dengan lembar kerja berikut.

Planet-planet dalam tata surya yang mengelilingi matahari bisa tetap berputar pada orbitnya karena ada gaya gravitasi yang membuat mereka mengorbit pada matahari. (Lembar Kerja Siswa 16, 16 April 2019)

Berdasarkan lembar kerja siswa 16 di atas siswa digolongkan dalam tingkatan baik sekali dimana siswa mampu menjelaskan fenomena benda makroskopis dalam materi tata surya yaitu planetplanet yang dapat tetap pada orbitnya juga mampu menyelidiki mengapa hal tersebut dapat terjadi. Hal ini ditandai dengan penjelasan adanya gaya gravitasi pada planet sehingga planet tersebut dapat tetap pada orbitnya untuk mengelilingi matahari. Siswa memiliki kemampuan memahami konsep sains dengan baik. Berdasarkan (Organisation for Economic Cooperation and Development, 2010) konsep sains dibutuhkan untuk memahami beberapa fenomena alam dan perubahannya.

Hasil analisis tes literasi sains menunjukkan bahwa $37,5 \%$ siswa dalam tingkatan baik sekali, $6,25 \%$ siswa dalam kategori baik dan 56,25\% siswa dalam tingkatan kurang baik sekali dalam aspek characteristic of science. Hasil analisis tes ini menunjukkan bahwa sebagian besar siswa kurang dalam aspek ini. Hal ini dibuktikan dalam lembar kerja siswa di bawah ini.

\section{Kategori Kurang Baik Sekali}

"Karena tata surya adalah benda-benda langit yang terdiri atas planet, matahari, komet, meteroid, asteroid, meteor." (Lembar Kerja Siswa 01, 16 April 2019)

Lembar kerja siswa 01 tergolong dalam kategori kurang baik sekali karena siswa memberikan penjelasan yang tidak sesuai dengan fenomena yang ditanyakan di soal. Siswa berusaha untuk memberikan deskripsi mengenai bendabenda makroskopis namun tidak menjawab pertanyaan di soal yang bertanya mengenai fenomena berputarnya planet pada orbitnya terhadap matahari pada lembar kerja siswa 01 .

\section{Science in Context}

Science in context merupakan aspek literasi sains yang menjelaskan kemampuan siswa dalam memaparkan fenomena atau situasi dalam kehidupan sehari-hari yang berdasarkan pengetahuan IPA, melihat relevansi pengetahuan IPA dalam kehidupan, mengaplikasikan secara luas pemahaman IPA di kehidupan sehari-hari, serta memberikan hubungan antara inovasi IPA dan kehidupan sosial-budaya (Shwartz et al, 2006).

Hasil tes literasi sains siswa dalam aspek ini menunjukkan bahwa sebesar 50\% siswa dikategorikan baik, $25 \%$ siswa dalam kategori cukup, $18,75 \%$ siswa dikategorikan kurang baik dan hanya $6.25 \%$ siswa dikategorikan sebagai kurang baik sekali. Hal ini dibuktikan dengan lembar kerja siswa dalam menjawab soal literasi sains sebagai berikut.

\section{Kategori Baik}

"3B. Dampaknya dapat menyebabkan mata kita akan tidak bisa melihat apa-apa ketika melihat gerhana matahari total. Oleh karena itu, kita harus memakai kacamata untuk melihat gerhana matahari total.

4A. Dapat menyebabkan bumi menjadi lebih panas dari sebelumnya. "(Lembar Kerja Siswa 25, 16 April 2019) 


\section{Kategori Cukup}

"3B. Dampak yang ditimbulkan oleh gerhana matahari total adalah bisa merusak kesehatan mata.

4A. Perubahan pemanasan global misalnya, dikatakan pada bulan April ini akan terjadi musim panas tetapi masih saja datang hujan."(Lembar Kerja Siswa 15, 16 April 2019)

Literasi sains yang digunakan dalam pembelajaran harus relevan dengan materi pembelajaran sains yang diajarkan di sekolah serta relevan dengan persepktif dan kondisi sosial siswa (Aalsvoort, 2004). Berdasarkan hasil lembar kerja siswa 25 di atas, siswa dapat menjelaskan dampak yang terjadi akibat fenomena sains berupa gerhana matahari total. Siswa juga mampu memberikan solusi yaitu dengan menggunakan kacamata saat gerhana matahari total terjadi. Siswa 25 juga dapat memberikan penjelasan mengenai akibat yang ditimbulkan dari fenomena pemanasan global. Siswa 15 dikategorikan cukup dikarenakan kurang memberikan penjelasan mengenai dampak fenomena sains yang ditanyakan soal. Siswa tidak memberikan solusi juga memberikan penjelasan yang kurang dipahami dalam menjawab mengenai dampak pemanasan global.

\section{High-Order Learning Skills}

\begin{tabular}{cccr}
\multicolumn{1}{c}{ Aspek } & High-Order & Learning & Skills \\
merupakan & kemampuan & siswa & untuk \\
mengidentifikasi & isu-isu & ilmiah, & mampu
\end{tabular}
mengajukan pertanyaan, dan mencari informasi dan mengaitkannya (Shwartz et.al, 2006). Hasil tes literasi sains siswa menunjukkan bahwa terdapat 43,75\% atau hampir setengah dari seluruh siswa yang mengikuti tes tergolong dalam kategori baik. Siswa yang tergolong baik sekali hanya 6,25\% siswa, kategori cukup sebesar $25 \%$ siswa, kategori kurang baik sebanyak $18,75 \%$ siswa.

Hal ini menunjukkan bahwa hampir sebagian besar siswa sudah mampu untuk mengidentifikasi isu-isu ilmiah terkait materi sistem tata surya. Berikut merupakan lembar kerja siswa yang menunjukkan kategori baik sekali dalam menjawab soal literasi sains yang diberikan.

\section{Kategori Baik Sekali}

"la. Karena jarak bumi dengan planet lain sangatlah jauh, sehingga matahari dan juga planet lain tampak seperti bintang dan planet tersebut mendapatkan cahaya dari matahari untuk membuat planet itu bersinar.

3a. Saat bulan menghalangi sinar matahari secara total maka akan terjadi kegelapan selama beberapa menit karena cahaya matahari ditutupi oleh bulan secara total dan akan kembali terang" (Lembar Kerja Siswa 16, 16 April 2019)

Berdasarkan lembar kerja siswa di atas dapat dianalisis bahwa siswa 16 mampu memberikan penjelasan yang detail mengenai fenomena ilmiah dimana planet lain tampak seperti bintang apabila terlihat dari bumi. Siswa 16 juga mampu menganalisis proses terjadinya gerhana matahari total. Menurut (Siregar, 2017), gerhana ini terbagi menjadi gerhana bulan dan gerhana matahari. Gerhana Bulan terjadi saat konfigurasi MatahariBumi-Bulan dimana sinar matahari terhalag oleh Bumi sedangkan gerhana Matahari terjadi saat Bulan-Bumi dan Matahari terletak pada satu garis lurus. Gerhana yang terjadi dapat tergolong gerhana total maupun gerhana parsial (sebagian).

\section{Affective Aspect}

Aspek afektif merupakan salah satu aspek literasi sains yang mengukur kemampuan sisswa dalam memahami dampak dari ilmu kimia dan aplikasinya serta menunjukkan minat pada isu-isu dan pembelajaran sains (Shwartz et.al, 2006). Berdasarkan hasil tes literasi sains, terdapat 37,5\% siswa dikategorikan sebagai kurang baik sekali sementara hanya terdapat $12,5 \%$ siswa dalam kategori baik sekali. Sedangkan kategori baik dan cukup masing-masing kategori sebesar 25\% siswa.

Hasil tes literasi sains menunjukkan bahwa siswa sebagian besar belum mampu menjelaskan dampak dari ilmu sains dan aplikasinya dalam kehidupan sehari-hari. Beberapa siswa tidak memberikan jawaban terhadap soal tersebut karena merasa kurang waktu. Berikut merupakan beberapa jawaban siswa pada lembar kerja. 


\section{Kategori Baik Sekali}

"4b. untuk mencegah pemanasan global adalah jangan menebang pohon sembarangan dan jangan membuang sampah sembarangan "(Lembar Kerja Siswa 23, 16 April 2019)

\section{Kategori Kurang Baik Sekali}

"4b. terjadinya perubahan musim, iklim dan

\section{cuaca”(Lembar Kerja Siswa 09, 16 April 2019)}

Berdasarkan lembar kerja di atas, siswa 23 mampu memahami maksud fenomena pemanasan global yang menjadi isu sains dalam kehidupan sehari-hari dan siswa 23 juga memberikan solusi untuk mencegah terjadinya fenomena ini. Di sisi lain, siswa 09 berusaha memahami soal mengenai pencegahan dan memberikan solusi namun masih kurang tepat. Berdasarkan analisis peneliti, siswa 09 memberikan dampak yang diakibatkan dari fenomena pemanasan global. Hal ini disebabkan kurangnya pemahaman siswa akan soal literasi sains yang diberikan sehingga dikategorikan sebagai kurang baik sekali.

\section{Identitas Budaya}

Pendekatan etnopedagogi memfasilitasi kesadaran budaya dan sosial siswa. Analisis identitas budaya siswa didapat dari data wawancara, reflektif jurnal, dan lembar kerja identifikasi siswa. Hampir setiap aspek pada pendekatan Etnopedagogi dapat mendukung terbentuknya kesadaran sosial budaya yang mencakup empati komunikasi, bertanggung jawab, disiplin, dan kepedulian sosial (Altugan, 2015). Penelitian ini dilakukan dengan mengintegrasikan konsep tata surya dalam pembelajaran sains dengan budaya Indonesia yang dapat dilihat pada Tabel 1 di bawah ini.

Tabel 1. Integrasi Sains dan Budaya dalam Pembelajaran Tata Surya

\begin{tabular}{lll}
\hline Budaya & Nilai & Deskripsi \\
Tradisi & Pelestarian & Tradisi mencari ikan atau \\
Balobe & alat & hewan laut selama \\
pada saat & tardisional. & gerhana bulan dengan alat \\
gerhana & & tradisional bernama \\
bulan & & Kalawai. \\
\hline
\end{tabular}

\begin{tabular}{ll}
\hline Budaya & Nilai \\
Tradisi & Pelestarian \\
Dolo-dolo & musik \\
dari Tidore & tradisional.
\end{tabular}

$\begin{array}{ll}\text { Tradisi } & \text { Perawatan } \\ \text { mengambil } & \text { kulit tubuh } \\ \text { beras dari } & \text { dengan } \\ \text { Bugis } & \text { menggunakan } \\ & \text { bahan } \\ & \text { tradisional. }\end{array}$

$\begin{array}{ll}\text { Tradisi } & \text { Penggunaan } \\ \text { Gejog } & \text { alat } \\ \text { Lesung } & \text { tradisional } \\ \text { dari } & \text { dalam } \\ \text { Yogyakarta } & \text { bertani. }\end{array}$

\begin{tabular}{lr}
\multicolumn{2}{c}{ Deskripsi } \\
Tradisi ini $\begin{array}{r}\text { bertujuan } \\
\text { untuk menyambut }\end{array}$
\end{tabular} gerhana bulan dan matahari.. Orang-orang di Tidore percaya bahwa pada saat ini akan ada makhluk raksasa bernama Suanggi yang menelan matahari atau bulan. Akibatnya, orang-orang di sana selalu membunyikan alat musik mereka (tifa) untuk membuat makhluk itu pergi.

Kelompok etnis Bugis mencuri beras sekitar 2 telapak tangan dari tetangganya untuk menghadapi gerhana bulan. Karena itu tradisi, tetangga tidak akan marah. Alasannya, pemilik beras akan melakukan hal yang sama. Nasi yang dicuri kemudian diolah menjadi bubuk.

Gejog Lesung terdiri atas lima hingga enam orang memukul mortir (tempat menumbuk padi) dengan alu (kayu yang ditumbuk), menyebabkan irama. Sebelum mesin penggiling diproduksi, mortar digunakan untuk memisahkan beras dari batang. Tetapi ada kepercayaan di antara orang Jawa pada zaman kuno bahwa gerhana matahari dan bulan terjadi karena ada Batara Kala raksasa yang memakan matahari. Manusia harus mengalahkan semua benda, termasuk mortir, sehingga Batara Kala memuntahkan matahari. Gejog Lesung juga dikaitkan dengan keyakinan mengusir raksasa selama gerhana bulan.

Salah satu ciri pendekatan etnopedagogi yaitu memperhatikan latar belakang budaya dan karakter siswa yang dapat menstimulasi munculnya kesadaran sosial. Hal ini dibuktikan oleh beberapa 
hasil wawancara dan reflektif jurnal siswa berikut ini.

"Hal yang membedakan saya dengan orang lain adalah misalnya bahasa daerah, adat istiadat, sistem kekerabatan." (Lembar Kerja Siswa 18, 09 April 2019)

$\begin{array}{lll}\text { Pertanyaan } & \text { : Darimana kamu berasal? } \\ \text { Siswa } 8 & \text { : Daerah Bima } \\ \text { Pertanyaan } & \text { : Apa yang kamu ketahui mengenai } \\ & \text { daerah asalmu? Apakah } \\ & \text { kebudayaan khas di daerah } \\ & \text { asalmu? }\end{array}$

Siswa $8 \quad$ : Daerah Bima terkenal dengan makanan dan minuman khasnya juga bahasa dan kebudayaan lokalnya. Contohnya, Salama Loko, Peta Kapanca, dan Compo Sampari.

Pertanyaan : Apa yang membedakan kamu dengan orang dari daerah lain?

Siswa 8 : Biasanya orang Bima menyukai makanan yang asam namun dari daerah lain yang saya tahu menyukai rasa pedas dan manis.

\section{(Lembar Kerja Identifikasi diri Siswa 8, 9 April 2019)}

Berdasarkan jawaban siswa dalam lembar kerja di atas terlihat bahwa siswa mampu mengidentifikasi daerah asalnya dan kebiasaan atau kebudayaan yang ada di daerahnya tersebut. Selain identifikasi, siswa juga memberikan penjelasan yang rinci mengenai perbedaan antara dirinya dengan orang lain. Kebudayaan siswa memberikan pengaruh terhadap cara siswa mengidentifikasi diri mereka (Yuli Rahmawati \& Taylor, 2018). Menurut Rahmawati et.al, 2019), pembelajaran dengan model etnopedagogi ini juga dapat mengembangkan kesadaran siswa atas budayanya seperti yang dikatakan siswa dalam wawancara berikut ini.

"Guru: apakah kamu menjadi semakin bertanggung jawab untuk mengenal kebudayaan di lingkunganmu dan menjaga kelestariannya? Mengapa?
Siswa: budaya perlu dilestarikan karena dari zaman dahulu para pahlawan kita yang sudah berjuang untuk melestarikan, dan adanya kita harus menjaga dan melestarikan budaya. Kalau tidak dilestarikan dampaknya adalah pandangan dari luar dan nanti budayanya hilang" (Wawancara Siswa 15, 09 April 2019)

Hasil wawancara di atas menunjukkan bahwa siswa 15 merasa semakin bertanggung jawab untuk mengenal kebudayaan di lingkungannya dan menjaga kelestariannya setelah belajar berbagai budaya berkaitan dengan materi sistem tata surya. Siswa 15 juga sadar bahwa budaya harus dilestarikan agar tidak punah atau hilang.

\section{PENUTUP}

Pembelajaran sains dengan model Etnopedagogy dapat mengembangkan literasi sains siswa dengan memberikan artikel tentang fenomena tata surya yang terintegrasi dengan budaya dari Bugis, Tidore, Yogyakarta, Solo, dan Bima. Hal ini dapat meningkatkan tanggung jawab siswa dalam melestarikan dan mengenal kebudayaan yang ada di lingkungannya maupun di daerah lain di Indonesia dalam proses pembelajaran sains. Selain itu, juga mampu mengembangkan rasa ingin tahu, cinta tanah air, kesadaran sosial dan budaya, peduli lingkungan, dan berpikir kritis. Hasil literasi sains siswa menunjukkan bahwa secara keseluruhan siswa dikategorikan dalam pencapaian baik sekali hingga cukup dengan total persentase $87,5 \%$. Namun masih ada sebesar $12,5 \%$ siswa yang masih tergolong kurang baik kemampuannya dalam memahami dan memberikan penjelasan berdasarkan aspek-aspek literasi sains yang dianalisis.

\section{DAFTAR PUSTAKA}

Aalsvoort, J. (2004). Logical positivism as a tool to analyse the problem of chemistry's lack of relevance in secondary school chemical education. International Journal of Science Education, 26, 1151-1168. https://doi.org/10.1080/09500690420002053 69 
Rahmawati, Y., Ridwan, A., Faustine, S., Syarah, S., Ibrahim, Mawarni, P.C.

Akhmetova, S. (2014). The ethnopedagogics of Kazakhstan: The formation and development. World Applied Sciences Journal, 29(8), 1050-1054. https://doi.org/10.5829/idosi.wasj.2014.29.0 8.13942

Altugan, A. S. (2015). The Effect of Cultural Identity on Learning. Procedia - Social and Behavioral Sciences, 190(November 2014), 455-458.

https://doi.org/10.1016/j.sbspro.2015.05.025

Burger, H. G. (1971). Ethno-Pedagogy: A Manual in Cultural Sensitivity with Techniques for Improving Cross-Cultural Teaching by Fitting Ethnic Patterns. (Second). Southwestern Cooperative Educational Laboratory.

Dragoş, V., \& Mih, V. (2015). Scientific Literacy in School. Procedia - Social and Behavioral Sciences, 209, 167-172. https://doi.org/10.1016/j.sbspro.2015.11.273

Elmi, A. A. (2010). Peace Education in Canada: Teacher Perceptions of the Cultivating Peace Education Program. Journal of Contemporary Issues in Education, 4(2), 4154. https://doi.org/10.20355/c5qg6x

Holbrook, J., \& Rannikmae, M. (2009). The Meaning of Scientific Literacy. International Journal of Environmental \& Science Education, 4(3), 275-288.

Klara, K., Baktiyar, O., Sandygul, K., Raikhan, U., \& Gulzhiyan, J. (2015). Ethnic pedagogy as an integrative, developing branch of pedagogy. Mediterranean Journal of Social Sciences, 6(1S1), 612-619. https://doi.org/10.5901/mjss.2015.v6n1s1p61 2

Martinez-Hernandez, K., Ikpeze, C., \& Kimaru, I. (2015). Perspectives on Science Literacy: A comparative study of United States and Kenya. Educational Research International, 4(2), 25.

Norris, S. P., \& Phillips, L. M. (2003). How Literacy in Its Fundamental Sense Is Central to Scientific Literacy. Science Education,
$87(2)$, 224-240.

https://doi.org/10.1002/sce.10066

Organisation for Economic Cooperation and Development. (2010). Assessing Scientific, Reading and Mathematical Literacy. In Assessing Scientific, Reading and Mathematical Literacy: A framework for PISA

2006.

https://doi.org/10.1787/9789524858366-fi

Rahmawati, Y., Ridwan, A., Rahman, A., \& Kurniadewi, F. (2019). Chemistry students' identity empowerment through etnochemistry in culturally responsive transformative teaching (CRTT). Journal of Physics: Conference Series, 1156(1). https://doi.org/10.1088/1742$6596 / 1156 / 1 / 012032$

Rahmawati, Yuli, Koul, R., \& Fisher, D. (2015). Teacher-student dialogue: transforming teacher interpersonal behaviour and pedagogical praxis through co-teaching and co-generative dialogue. Learning Environments Research, 18(3), 393-408. https://doi.org/10.1007/s10984-015-9191-4

Rahmawati, Yuli, \& Taylor, P. C. (2018). "The fish becomes aware of the water in which it swims": revealing the power of culture in shaping teaching identity. Cultural Studies of Science Education, 13(2), 525-537. https://doi.org/10.1007/s11422-016-9801-1

Rychen, D S, \& Salganik, L. H. (2003). Key competencies for a successful life and a well-functioning society. In Dominique Simone Rychen \& L. H. Salganik (Eds.), OECD Definition and Selection of Competencies Final Report. Hogrefe \& Huber Publishers. https://doi.org/10.1080/2159676X.2012.7129 97

Shen, B. S. P. (1975). Views: Science Literacy: Public understanding of science is becoming vitally needed in developing and industrialized countries alike. American Scientist, 63(3), 265-268. http://www.jstor.org/stable/27845461 
Shwartz, Y., Ben-Zvi, R., \& Hofstein, A. (2006). The use of scientific literacy taxonomy for assessing the development of chemical literacy among high-school students. Chem. Educ. Res. Pract., 7(4), 203-225. https://doi.org/10.1039/B6RP90011A

Siregar, S. (2017). Fisika Tata Surya. Fakultas Matematika dan Ilmu Pengetahuan Alam Institut Teknologi Bandung. https://fmipa.itb.ac.id/wpcontent/uploads/sites/7/2018/02/e-BookFisika-Tata-Surya.pdf\%0D

Toleubekova, R., \& Zhumataeva, E. (2018). The role of ethnopedagogy in shaping positive attitudes towards traditional values of
Kazakh people among master's students majoring in education in Kazakhstan. Problems of Education in the 21st Century, 76, 834-846. https://doi.org/10.33225/pec/18.76.834

Trefil, J. (2008). Science Education for Everyone: Why and What? Liberal Education, 94(2), 6-11.

Valeeva, R. A. (2015). Editorial. An International review of the possibilities of educational environment in the development of students and teachers. International Journal of Environmental and Science Education, 10(4), 514. https://doi.org/10.12973/ijese.2015.275a.. 